GÖKER AKSOY, Ph.D. Candidate ${ }^{1}$

(Corresponding author)

E-mail: gokeraksoy@itu.edu.tr

KEMAL SELÇUK ÖĞÜT, Ph.D. ${ }^{1}$

E-mail: oguts@itu.edu.tr

${ }^{1}$ Istanbul Technical University

Department of Civil Engineering

Istanbul, 34469, Turkey
Traffic on Motorways

Preliminary Communication

Submitted: 5 Mar. 2018

Accepted: 2 Oct. 2018

\title{
DISCHARGE FLOW RATE CHANGE UNDER RAINY CONDITIONS ON URBAN MOTORWAYS
}

\begin{abstract}
Queue discharge flow is the most frequently observed phenomenon on urban motorways when demand exceeds capacity. Once a queue is formed, congestion arises, and the number of vehicles that can pass from downstream reduces. This reduction phenomenon is defined as the capacity drop and calculated by taking the difference between capacity and discharge flow at a road section. Obviously, this capacity drop exists after an onset of congestion and may increase in relation to weather conditions, such as rain, snow, or fog, which cause longer queues and delays. In this paper, the effect of rain on discharge flows is investigated and compared with sunny days on Istanbul urban motorways. Besides, rain precipitation during congestion is considered and related to discharge flow. Four different motorway sections were analyzed, and up to 37\% discharge flow reduction was determined between sunny and rainy conditions. Motorway sections with higher free flow speed (FFS) were found to be more affected by rain, and discharge flow reduction was bigger compared to the section with the lowest FFS. For 1 $\mathrm{mm} / \mathrm{m}^{2} / \mathrm{h}$ of precipitation, the discharge flow is estimated as $1,719 \mathrm{pcu} / \mathrm{h} /$ lane when FFS is $84 \mathrm{~km} / \mathrm{h}$, and as 1,560 $\mathrm{pcu} / \mathrm{h} /$ lane if FFS is $104 \mathrm{~km} / \mathrm{h}$.
\end{abstract}

\section{KEY WORDS}

discharge flow; capacity drop; rain effect; motorway;

\section{INTRODUCTION}

Traffic congestion is a daily routine, especially for commuters, who use their private cars during morning and evening peak hours. When road section capacity becomes insufficient compared to demand, congestion inevitably occurs during peak hours.

Congestion duration is definitely related to both demand and bottleneck capacities. It is obvious that once the volume reaches a certain threshold value on the upstream, the downstream cannot deal with it, and bottleneck activation takes place. Once a queue is formed, if the demand remains the same, less flow can be discharged at the downstream. This phenomenon is called 'capacity drop' and could be defined as a reduction at mainstream flow after onset of queue on the upstream, or basically the difference between capacity and discharge flows [1-3]. In this statement, the discharge flow indicates the outflow of congested vehicles without influence of any downstream queues. Besides, the capacity is pointed out as maximum sustained 15-min flow rate of that road, and it must be repeated over time. Since capacity is not stable, both capacity and discharge flow may vary, even in the same section. Additionally, they can vary between different traffic lanes in the same cross-section of a carriageway [4].

Explicitly, capacity drop and discharge flow express a decrease of infrastructure performance. Capacity drop has a strong relation with delays and can affect commuters negatively. To prevent its negative effects, various traffic control strategies are applied in the literature [5-7]. The value of discharge flow is not constant; it changes with high standard deviation in each occurrence, even in the same section [8-10]. It is difficult to clarify the effects of discharge flow on traffic since it takes a wide range of values. In addition, adverse weather conditions such as rain and snow make it more complex to explain.

This paper mainly focuses on discharge flow change on basic motorway sections in İstanbul, where the flow is simply interrupted due to traffic demand. The queue discharge flow is assumed as the maximum flow rate constituted by the queued vehicles, while the traffic flow speed increases from congested to uncongested states for both rainy and sunny conditions. The queue discharge flows are determined daily for each traffic sensor called RTMS (Remote Traffic Microwave Sensor) in relation to rain precipitation occurring in the course of congestion. In order to analyze discharge flow change, firstly, a comparison is made in percent frequencies between rainy and sunny conditions. Secondly, the discharge flows which are observed under the rain precipitation are analyzed within themselves. Congestion time period is used as a time interval, and total rainfall amount is used for precipitation. A novel model is estimated between discharge flow and total rain precipitation during congestion in relation to the 
free flow speed (FFS) of each section. FFS is determined as the average of speeds when the flow rate is below a constant threshold. This value is determined by considering speed-flow rate relationships at each section. This is because it is known that speeds are not affected by the number of vehicles in traffic flow below this threshold. In other words, drivers can decide their speeds freely below this point. Finally, the averages of those vehicle speeds are considered as FFS of each section. From the used RTMS in this study, this threshold value is determined as $500 \mathrm{pcu} / \mathrm{h} /$ lane for sunny and $400 \mathrm{pcu} / \mathrm{h} /$ lane for rainy records. As a last step, the discharge flows observed on sunny days with clear sky are compared to rainy days in order to clarify percent reduction in discharge flows. Accordingly, only queued vehicles without the influence of any downstream flow are used to determine the discharge flows at four different sites.

The analyses were conducted on the Trans European Motorway (TEM), which is the crucial main urban motorway in Istanbul, based on 15-min aggregated traffic flow characteristics. To accomplish this study, time-speed and rescaled cumulative flow rate graphs are used in order to determine the discharge flows precisely as mentioned in the literature $[11,12]$.

\section{LITERATURE REVIEW}

Since both human behavior and traffic flow itself are complex processes, it could be hard to explain either the variation in discharging flow or the rain effects on it. The variation is caused due to the composition of vehicles in discharging flow, the intensity of rain affecting the queued vehicles, the road surface conditions, or even the time of a day.

In the literature, a wide range of studies on capacity drop and queue discharge flow generally focus on capacity drop at motorway bottlenecks. Since capacity drop is defined as the difference between road capacity and queue discharge flow, both of them provide a comprehensible method for detailed analyses. However, both capacity and discharge flow can vary, even in the same section. It is not a comprehensible method to analyze rain effects with capacity drop. For this reason, aiming this study at investigating discharge flow change is a more explanatory way, since it is less biased.

Hall and Agyemang-Duah [3] and Banks [1, 2] first indicated the decreasing flow rates after formation of queues, in other words, capacity reduction at motorway bottlenecks. Hall and Agyemang-Duah [3] found the maximum flow rate reduction as $5 \%$ to $6 \%$ at motorways from empirical observations after congestion occurs. They similarly pointed to greater consideration of passenger car equivalents in calculations. On the other hand, Banks [1] observed lower capacity reduction (3.2\%).
Although this paper mainly focuses on discharge flow change under rainy conditions, the published papers on this subject are quite limited. Most of the studies are related to road capacity change according to weather conditions or capacity drop analyses without weather effects. The lane-based changes of traffic flow characteristics were evaluated by Rijavec and Semrov [4] but not for discharge flow. Additionally, few studies calculate discharge flows, generally excluding weather effects. One of those studies, written by Elefteriadou and Lertworawanich [8], mentioned that the maximum discharge flow varied between $1,431 \mathrm{veh} / \mathrm{h} /$ lane to 2,241 veh/h/lane during a 15-min aggregation interval without considering weather effects. The standard deviation was 140 veh/h/lane in each study site. Additionally, it is mentioned that the numerical value of discharge flow varies and has a relatively large range, e.g. several hundred veh/h/lane.

Discharge flow, which is constituted by queued vehicles (in congested regime), is relatively low compared to capacity flow. This may happen because of the increase in vehicle passage time that occurs when speed decreases [2]. In addition, according to the observations used in this study, flow is comprised of accelerating vehicles. Since they can have different engine powers and driver characteristics, their speeds can be different, which leads to variations of average vehicle headways.

Cassidy and Rudjanakanoknad [7] observed discharge flows as low as 1,560 veh/h/lane and as high as $1,856 \mathrm{veh} / \mathrm{h} /$ lane on California motorways. On the same motorways, Chung et. al. [9] noticed discharge flows in sunny conditions from 1,680 veh/h/lane to $1,856 \mathrm{veh} / \mathrm{h} /$ lane, and the discharge flow from one observation in light rain was found to be 1,760 veh/h/ lane. Bertini and Malik [13] observed discharge flows for sunny days between 2,115 and 2,130 veh/h/lane, while for light rain the discharge flow was about 2,145 veh/h/lane on Minneapolis motorways. Results of several studies indicate a wide range of discharge flow values even for similar road types. Bertini and Leal [14] observed discharge flows that varied from 1,575 veh/lane to 1,750 veh/lane on M4 Motorway, United Kingdom. Cassidy and Bertini [15] indicated the minimum discharge flow as $1957 \mathrm{veh} / \mathrm{h} /$ lane and the maximum as 2,167 veh/h/lane for spring and winter observations during clear skies at two different sites.

Oh and Yeo [16] revealed a change in discharge flow by lane excluding weather effects. For a threelane highway, the discharge flow in the leftmost lane appeared as 2,074 veh/h/lane, 1,954 veh/h/lane for the middle lane, and 1,742 veh/h/lane for the rightmost lane. A five-lane highway observation contains more surprising results, as for the discharge flow in the leftmost lane was close to 2,231 veh/h/lane, while for the leftmost lane it amounted to 1,582 veh/h/lane. 
There are no explanatory studies that reveal a change in discharge flow under the effect of rain precisely. Only several studies mentioned rain effect, when researchers encountered rainy discharge flow. Although there is no information about discharge flow change in rainy conditions, its effect could be somewhat comprehensible from previous studies which are based on capacity change. The rain precipitation considered by Jones and Goolsby [17] indicates a $14 \%$ to $19 \%$ motorway capacity reduction. Kleitsch and Cleveland [18] stated that more than $1 \mathrm{~mm} / \mathrm{h}$ rain precipitation causes a motorway capacity decrease of up to $8 \%$. Almost in all studies capacity reductions are significant, as Brilon and Ponzalet [19] mentioned 18\%, Balke et. al. [20] recorded 6.8\%, while Hranac et. al. [21] found a $10 \%$ to $11 \%$ capacity reduction. Additionally, Holdener [22] remarked that wet road surface causes road capacity reduction between $8 \%$ and $24 \%$.

The results of previous studies have shown that there is variability in discharge flows. However, few studies mention the effect of rain on discharge flow. The main concerns of those very limited studies were not to investigate the effect of rain on discharge flow. Their authors typically encountered a few rainy observations. There is no in-depth analysis about the effect of rain on discharge flows. Unlike the studies encountered in the literature, this paper compares rainy and sunny discharge flows and the effect of rain precipitation on discharge flow on urban motorways.

\section{DATA COLLECTION AND STUDY SITES}

In order to reveal discharge flow change with respect to rain, macroscopic traffic flow characteristics were gathered, such as speed, volume, and vehicle composition per lane via RTMSs in 2-min intervals (constituting 720 observations per day). RTMSs were operated by the Traffic Management Center, Municipality of İstanbul. Measured traffic flow records were gathered per lane and then converted to road values from all RTMSs. Summation of vehicle counts for each lane was used as road base volume, while weighted average of speeds for each lane (considering volume) was used as road base flow speed. In each lane, volume was used as the weight to calculate average speeds. Since in each traffic lane different volume counts were observed, the logical way to determine road base speed was to calculate from weighted averages. As a result, road based average flow speeds were obtained in addition to vehicle counts and vehicle composition.

The weather records, including the rain precipitation, were obtained from Turkish State Meteorological Service with road weather stations at 1-min intervals. All those stations were constructed for road weather observation purpose and represent weather events exactly for the nearest RTMS. There are 100 meteorological stations within istanbul to observe weather events, and 40 of these stations are used for regional weather observation purposes only, while 60 of them are for road weather information. Rain precipitation accuracy is $0.2 \mathrm{~mm} / \mathrm{m}^{2} / \mathrm{min}$, and 1,440 observations are recorded per day.

In this research, four-month traffic and weather records (between November 2015 and February 2016) are evaluated by aggregating them to 15-min, similar to previous studies $[8,16,23]$. The approximate locations of both traffic and weather sensors are shown in Figure 1.

The nearest weather station to each section is considered for the analyses of weather and traffic flow data fusion process, which is completed in two steps.

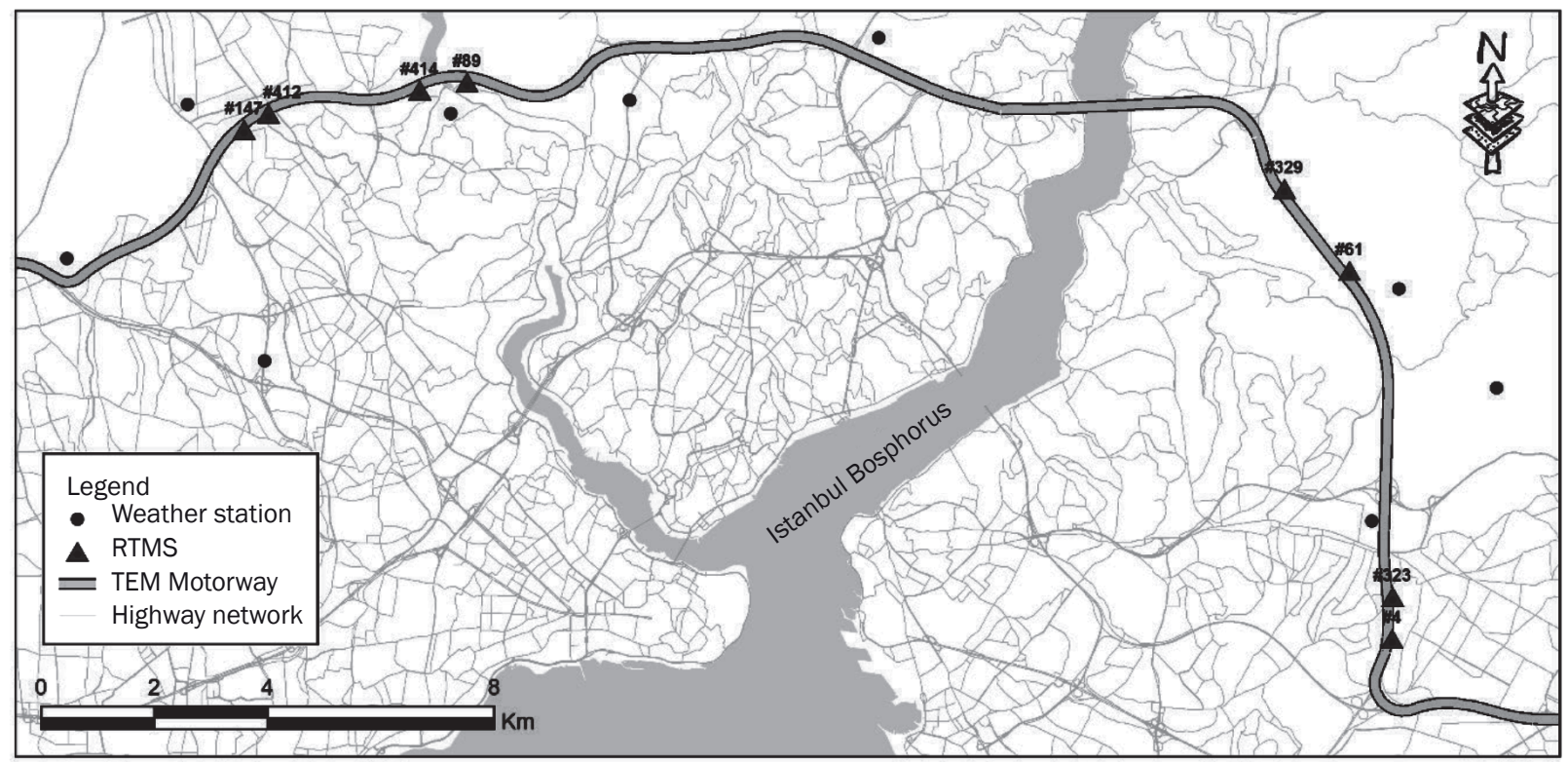

Figure 1 - Approximate locations of traffic and weather sensors along TEM 
Firstly, 1-min weather observations are converted to 15-min intervals. It is done simply with a summation of consecutive 15 precipitation records. In the second step, 2-min traffic flow observations are aggregated within each 15-min time interval. For this process, the first 7 and a half of the $8^{\text {th }}$ record are considered for the traffic records. As for the $8^{\text {th }}$ record, half of the vehicle count and $1 / 2$ weight for speed are considered. After these two steps, rain precipitation is simply matched with the traffic flow records, since numbers of observations are equal for each day. It should be noted that both weather and traffic records were recorded at the end of the observation time interval, and this data fusion approach is relatively easy, since there is no problems with the time accuracy linkage.

Eight different RTMSs at four different sections on TEM were selected as study locations, with four of them on the Asian side and others on the European side. TEM is one of the main arterials in İstanbul, and it connects Asia and Europe with quite high urban and intercity traffic demands. Discharge flows change is analyzed on basic motorway sections, which are far from off and on ramp sections, as shown by the approximate locations of RTMSs in Figure 2. Therefore, congestion had to start because of bottleneck activation without any external impacts like incidents or vehicle breakdowns. Additionally, traffic flow records are more reliable for basic motorway sections in terms of making fair comparisons, since RTMSs have higher miscounting errors at merge and diverge sections. These miscounting errors originate mostly from the lack of lane discipline, especially at motorway merges and diverges. The main aim of this study is not to analyze the formation of queues at on-ramp bottlenecks, but on the contrary, it is for clarification of how queues discharge and change with rain precipitation on basic motorway sections.

The traffic of heavy vehicles, except buses, is restricted during peak hours (06:30-10:30 and 16:0022:00) in order to reduce traffic demand along TEM urban sections. Additionally, speed limits are applied as $120 \mathrm{~km} / \mathrm{h}$ for passenger cars, $100 \mathrm{~km} / \mathrm{h}$ for buses, and $90 \mathrm{~km} / \mathrm{h}$ for heavy trucks at TEM, as well as all motorways in Turkey. RTMSs can only distinguish vehicles according to their length for vehicle composition. Details of traffic records allow using only two clusters for vehicle composition, as heavy and light vehicles. In the analyses, heavy vehicles are converted to passenger car unit (PCU) by using the 1.5 coefficient as indicated in HCM 2010 [24]. RTMSs classify vehicles of length under $10 \mathrm{~m}$ as light, otherwise as heavy vehicles. For this reason, there is no distinguishing vehicles in more detail, such as heavy trucks, recreational vehicles, or intercity buses from those observations. Long vehicles are multiplied with the coefficient of 1.5 and added to regular vehicle counts to find PCU for each traffic flow record.

All four sections suffer from high intercity traffic demand, especially from commuters. Even though traffic is restricted for heavy vehicles during peak hours, substantial intercity public transport and service buses regularly use those sections every day. From the fourmonth traffic observations, heavy vehicle percentage shows little variation from site to site. The highest average heavy vehicle percentage is observed at Section II as $21.96 \%$, while the lowest at Section I as $15.04 \%$. Dense residential areas between Sections I and II may cause an increase in average heavy vehicle percentage since TEM is the single main arterial for heavy vehicles passage. For Sections III and IV, heavy vehicle

Section I (European side)

Section II (European side)
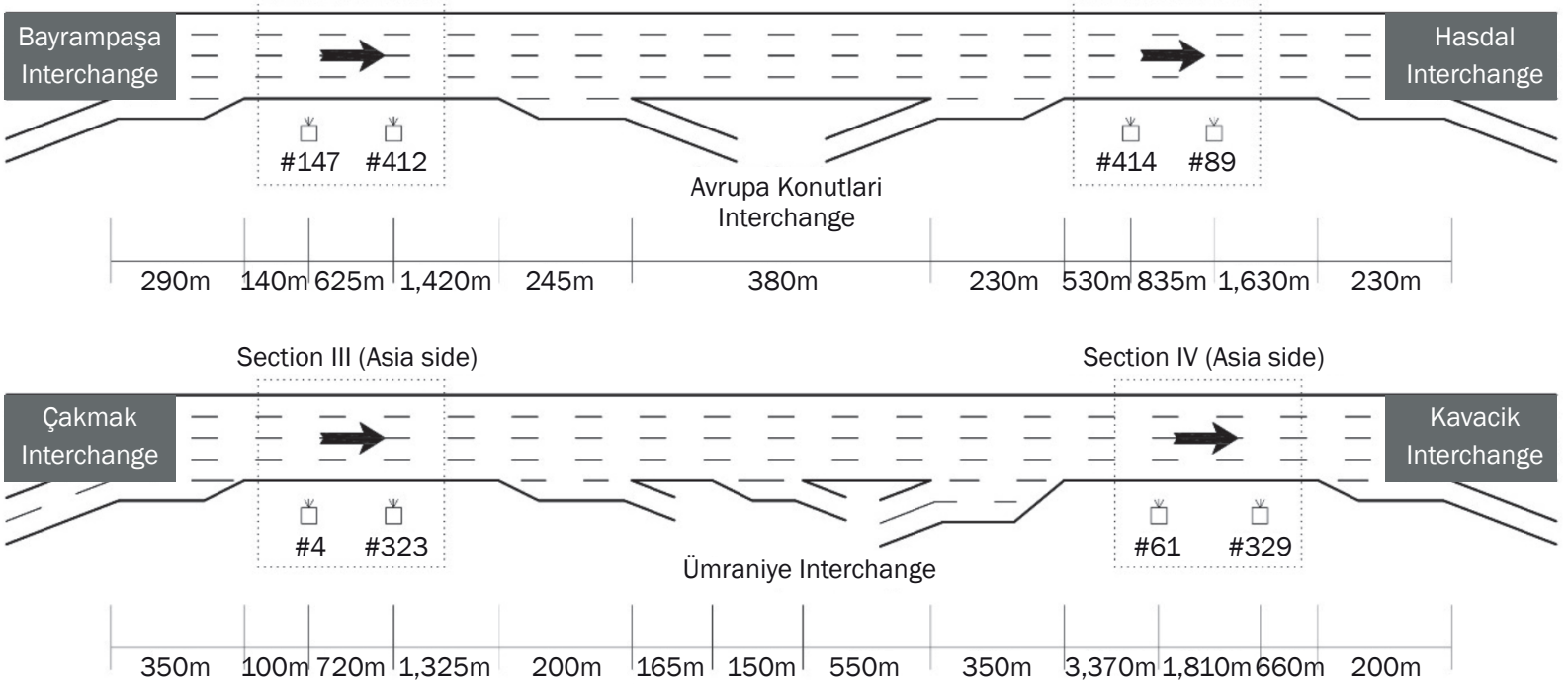

Figure 2 - Approximate location of four sections with eight RTMSs 
percentages are calculated as $19.44 \%$ and $16.04 \%$, respectively. Traffic congestion at these sections originates from extremely high traffic demand, especially during weekdays. Hence, Sections I to IV suffer from daily traffic congestion even in sunny days. However, with rain influence both congestion and its negative effects increase. From this perspective, the analyzed sections are highly convenient to study and understand the possible effects of rain precipitation.

To sum up these explanations, by considering the presence of rain during a discharge period, 15 rainy days were determined. Moreover, it is assumed that the rain started at least one hour before the discharge period. In order to minimize the daily discharge flow change, the days just after these rainy days were determined as sunny days. As a result, 30 days (15 sunny, 15 rainy) are considered for discharge flow analyses. Discharge flows are identified for all RTMSs during 30 days.

\section{METHODOLOGY}

The most crucial and difficult part of the study is the accurate determination of the queue discharge flows for both sunny and rainy days, since the study is based on them. First, congestion originated from any incident or vehicle breakdown is identified and eliminated from the data set, since it generates a bottleneck and affects routine traffic flow behavior.

Discharge flow is determined as the observed maximum flow rate on field after bottleneck activation and prior to its full recovery. This flow could be distinguishable through flow regime, which changes from congested to uncongested flow conditions similar to previous studies $[1,8]$.

Determination of incidents or vehicle breakdowns is not enough for precise identification of discharge flows. Due to unpredictable nature of traffic flow, it is necessary to be sure that when queue discharge flow is observed at any section, a queue must exist upstream, while downstream it has free flow. In order to clarify how this process is done, Figure 3 is given for three consecutive RTMSs (\#147, \#412, and \#413, respectively) in Section I for the rainy day of 11 February 2016. As indicated in Figure 2, RTMS \#412 is located $625 \mathrm{~m}$ after RTMS \#147. A third RTMS (\#413) is used for verification of traffic state in Figure 3 , and it is located $730 \mathrm{~m}$ after RTMS \#412. The same road geometric standards are valid for RTMS \#413, while it is not used for discharge flow change determination. The purpose of its usage is to identify correct discharge flows for the RTMSs in Section I, which are given in Figure 2. A similar approach is applied for the other sections in order to clarify the discharge flows.

Figure 3 is presented by using 15-min shifted speeds of RTMSs \#147, \#412, and \#413. Considering the flow direction, the first RTMS is \#147, and the latest is \#413. If congestion originates due to bottleneck activation, it can be identified by the first speed reduction observation from RTMS \#413, just as seen in Figure 3. Then the queue reaches RTMSs \#412 and $\# 147$, respectively, and similar speed reductions are observed after some time. Speed reduction trends of these consecutive three RTMSs are simply evidence of an activated bottleneck. However, the most important part is the clarification of discharge flow, which can be observed during a speed increase (in this case around 08:00) and must be verified by checking consecutive speed increases as before. The first speed increase must be observed on the downstream RTMS \#413, while the latest on the upstream RTMS \#147. Figure 3 similarly proves this consistent change between RTMSs. This procedure is applied for both rainy and sunny days of eight RTMSs'. It should be noted that only two RTMSs in each section are considered for discharge flow analyses, and for this reason downstream RTMSs are not presented in Figure 2. Although this procedure is applied to generate the data set, actually it is not important as to how queues are formed. Even though they could form with queue spillbacks or incidents, the crucial point is how those flows are discharged, and this must be verified with the speed increase part in Figure 3.

After the confirmation of speed decreases, which originate solely from bottleneck activation, as a second step the discharge flow is determined. Discharge

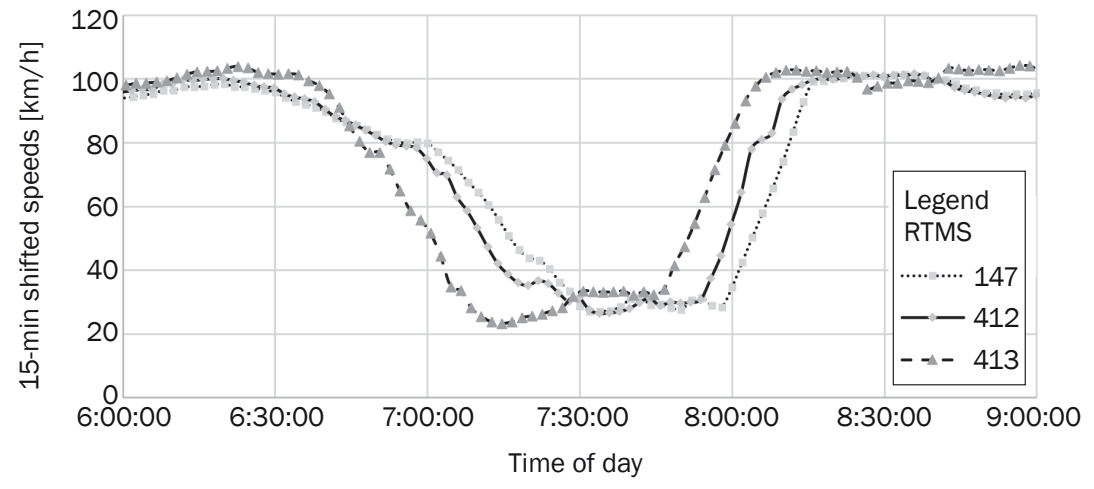

Figure 3 - Time series of speeds between adjacent RTMSs in Section I 
flows are difficult to differentiate among observations while flow state changes from congested to free flow conditions. A precise way to specify them is to use rescaled cumulative flow and speed time series together. A background volume is subtracted to obtain rescaled cumulative flow which magnifies the changes on volume. As an example, changes of speed and rescaled cumulative flow are shown for RTMS \#147, which belongs to 9 November 2015 between 11:40 to 14:40 for a sunny day in Figure 4.

From Figure 4, it can be concluded that congestion started after 12:00 and fully recovered around 13:30. From this figure, the beginning of congestion as well as the discharge flow can be identified with the determination of two changes. The first one is the change of rescaled cumulative curve slope and the second one is the change of flow speed. Point A indicates the change of rescaled cumulative curve slope, which means less vehicles began to pass during speed reduction compared to before. This point is the congestion start point. Similarly, during the speed increase (approximately between 13:12 and 13:30) the rescaled cumulative flow slope change stands out at 13:20 (indicated with point $\mathrm{B}$ ), which means the maximum output that passed after the congestion is determined as 6,486 pcu/h/4 lanes (1,621 pcu/h/lane). As a background (reference) volume, 4,350 pcu/h/4 lanes $(1,088 \mathrm{pcu} / \mathrm{h} /$ lane $)$ is determined in order to clarify the change in slope clearly. It should be noted that even when different background volume is used, points $A$ and $B$ should remain the same. However, it could be difficult to distinguish those points with different background volumes. Because of this, background volumes are selected as site specific.

Sunny discharge flow determination, just like in Figure 4, is relatively easy, since rainfall must additionally be taken into account for rainy days. Consequently, during a speed increase in rainy days, either rainfall must exist or road surface must be wet. Since such occurrence is rather rare, there is a relatively small number of rainy discharge flow observations.

By this approach, every single discharge flow is determined attentively and accurately day by day. Finally, two different data sets are generated, one for sunny and another for rainy observations.

\section{DATA ANALYSIS AND FINDINGS}

Compiling precise data sets from a large amount of data would mean nothing without determining effective analysis methods. In this study, it is preferred to use rain precipitation time in relation to congestion time. In this way, total rainfall amount is calculated during a congestion time period (time interval between points $A$ and $B$ in Figure 4), and its hourly equivalent is named rain precipitation, its unit being $\mathrm{mm} / \mathrm{m}^{2} / \mathrm{h}$.

Along Istanbul urban motorways, 84 sunny and 52 rainy discharge flows were determined from four sections, where two RTMSs were present at each section. For each RTMS used in this study, Table 1 includes discharge flow descriptive statistics for both sunny and rainy days. The data set includes discharge flows as well as FFSs for rainy and sunny days, average rain precipitation during congestion, standard deviations of discharge flows and average discharge flow reductions compared to sunny days.

Table 1 includes key parameters at each section like average discharge flows, FFSs as well as average rain precipitation during the congestion time period. Along all analyzed sections, lane width is constant $(3.75 \mathrm{~m})$, shoulder lanes are present and there are four lanes in each direction. Due to some environmental reasons, such as slight gradient change and existence of roadside distractions, sections' FFSs could differ from each other. However, it could be concluded from the observation of flow rate-speed graphs of each RTMS that the capacity of each section is approximately identical. Amongst four sections, Section III has the lowest and

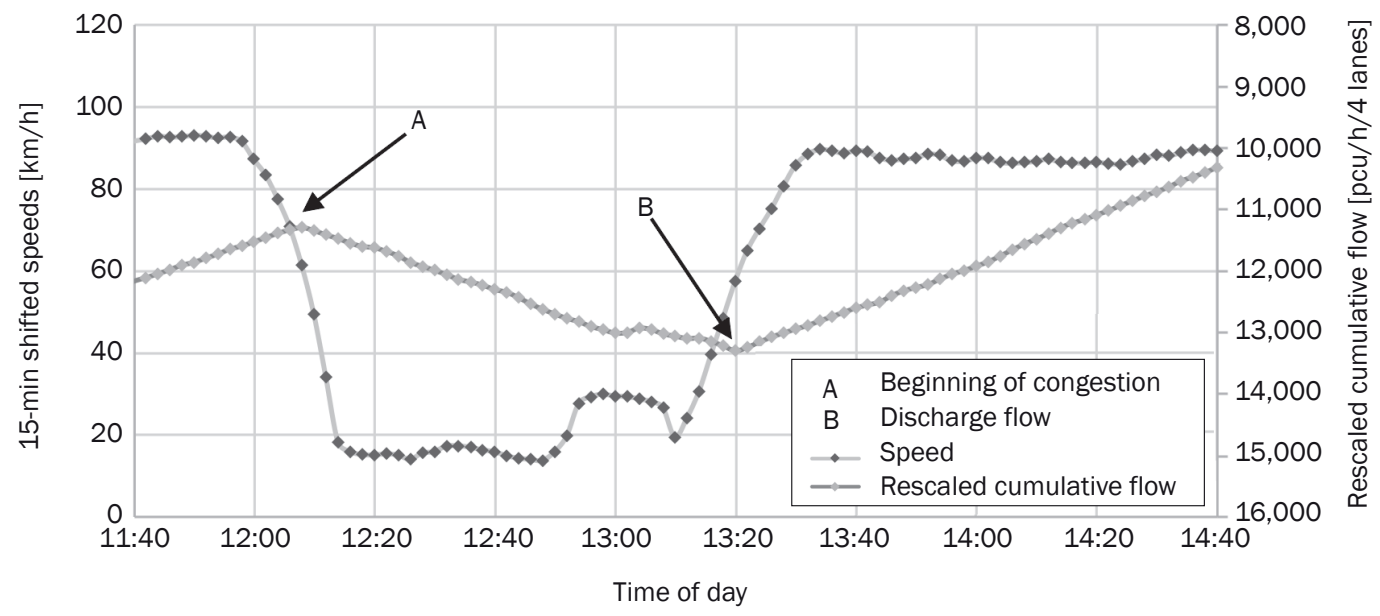

Figure 4 - Determination of queue discharge flow for RTMS \#147 on 9/11/2015 
Aksoy G, Öğüt KS. Discharge Flow Rate Change Under Rainy Conditions on Urban Motorways

Table 1 - Average discharge flow rates and statistical values on each RTMS

\begin{tabular}{|c|c|c|c|c|c|c|c|}
\hline \multirow{2}{*}{ Group } & \multirow{2}{*}{ RTMS } & \multirow{2}{*}{$\begin{array}{c}\mathrm{FFS} \\
{[\mathrm{km} / \mathrm{h}]}\end{array}$} & \multirow{2}{*}{ Weather } & \multirow{2}{*}{$\begin{array}{l}\text { Average rain precipitation } \\
\qquad\left[\mathrm{mm} / \mathrm{m}^{2} / \mathrm{h}\right]\end{array}$} & \multicolumn{3}{|c|}{ Discharge flow [pcu/h/lane] } \\
\hline & & & & & Average & Standard deviation & Decrease [\%] \\
\hline \multirow{4}{*}{1} & \multirow{2}{*}{147} & 99 & Sunny & & 1,493 & 190 & \\
\hline & & 93 & Rainy & 3.55 & 936 & 34 & 37 \\
\hline & \multirow{2}{*}{412} & 102 & Sunny & & 1,562 & 168 & \\
\hline & & 93 & Rainy & 2.45 & 1,328 & 177 & 15 \\
\hline \multirow{4}{*}{ II } & \multirow{2}{*}{089} & 101 & Sunny & & 1,700 & 110 & \\
\hline & & 91 & Rainy & 1.62 & 1,432 & 234 & 16 \\
\hline & \multirow{2}{*}{414} & 104 & Sunny & & 1,687 & 129 & \\
\hline & & 94 & Rainy & 1.65 & 1,410 & 236 & 16 \\
\hline \multirow{4}{*}{ III } & \multirow{2}{*}{004} & 88 & Sunny & & 1,806 & 74 & \\
\hline & & 80 & Rainy & 1.36 & 1,719 & 124 & 5 \\
\hline & \multirow{2}{*}{323} & 84 & Sunny & & 1,690 & 82 & \\
\hline & & 78 & Rainy & 1.16 & 1,602 & 111 & 5 \\
\hline \multirow{4}{*}{ IV } & \multirow{2}{*}{061} & 94 & Sunny & & 1,696 & 122 & \\
\hline & & 90 & Rainy & 2.29 & 1,282 & 232 & 24 \\
\hline & \multirow{2}{*}{329} & 99 & Sunny & & 1,800 & 148 & \\
\hline & & 92 & Rainy & 1.61 & 1,545 & 346 & 14 \\
\hline
\end{tabular}

Section II the highest FFS in sunny days. For a rainy FFS, Section III has the lowest while others have almost identical values. In each RTMS, the average discharge flows in rainy conditions are relatively low compared to sunny conditions. In order to indicate how rain affects traffic flow, Figure 5 shows clearly the change in speed-flow rate diagrams between sunny and rainy days for one RTMS in each section.

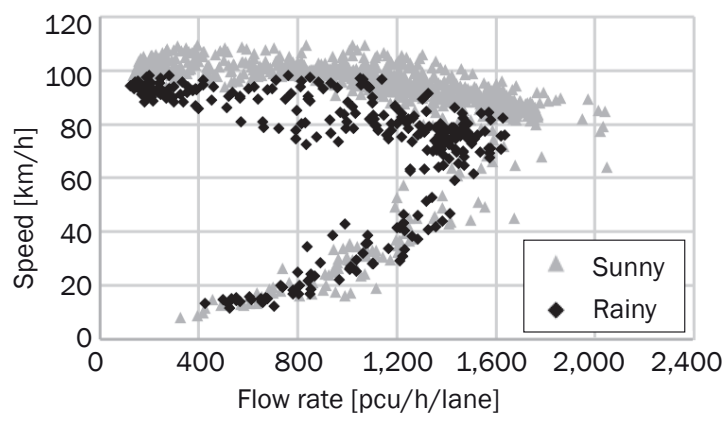

a) RTMS \#147 in Section I

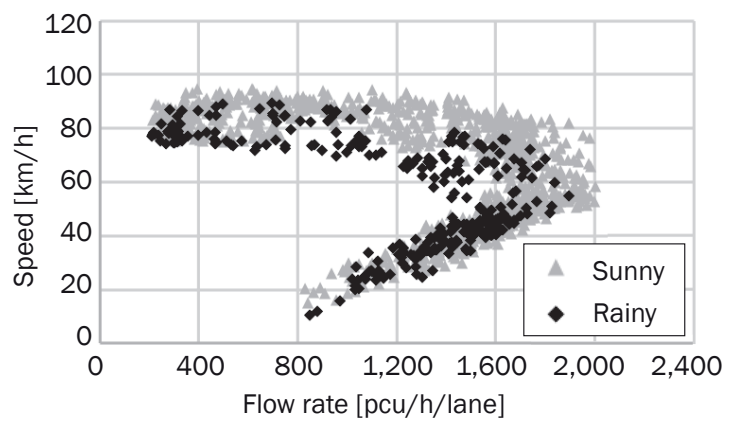

c) RTMS \#323 in Section III
The rainy observations in each section are only collected if rainfall exists or road surface is wet. It is assumed that road surface remains wet for 15 minutes after rain stop. From these four speed-flow rate relationships, the most obvious differentiation shows up on FFSs and change in speed-flow rate relationships at free flow conditions. Rain clearly affects traffic flow compared to sunny days. Although FFSs are different

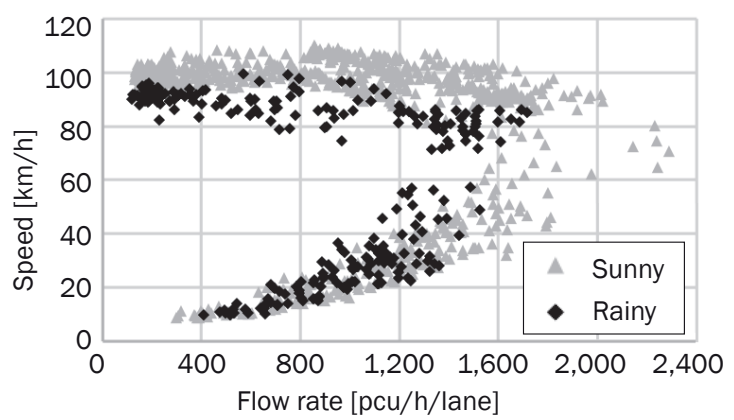

b) RTMS \#89 in Section II

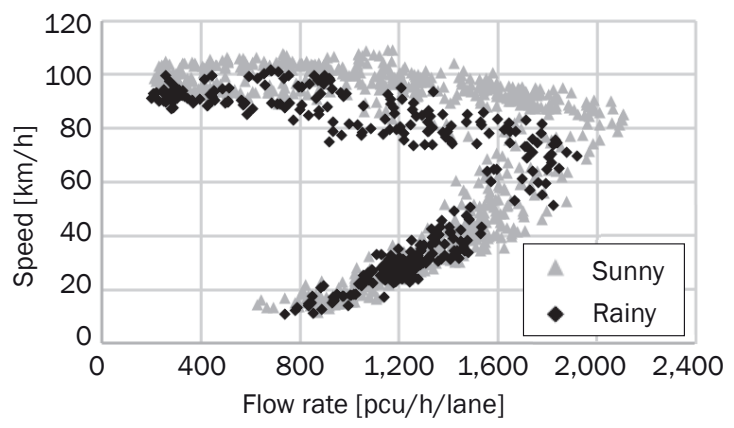

d) RTMS \#329 in Section IV

Figure 5 - Speed-flow rate diagram between sunny and rainy days 
from site to site, there is no obvious difference on the congested flow conditions between sunny and rainy days. The evaluation of each section is as follows.

Section I: In sunny days for two RTMSs inside the section, FFSs, are slightly different from each other, while they are equal in rainy days. Average discharge flow at RTMS \#147 is relatively low (936 pcu/h/lane) in rainy conditions, which means a $37 \%$ reduction of discharge flow compared to average sunny discharge flows (1493 pcu/h/lane). However, from four rainy discharge flows in RTMS \#147, the hourly equivalent of rainfall during the congestion is observed as high as $4.57 \mathrm{~mm} / \mathrm{m}^{2} / \mathrm{h}$ with an average $3.55 \mathrm{~mm} / \mathrm{m}^{2} / \mathrm{h}$, as indicated in Table 1. On the other hand, the average rainfall for RTMS \#412 is calculated as $2.45 \mathrm{~mm} / \mathrm{m}^{2} / \mathrm{h}$, which means Section I has the highest precipitation amongst others. It is obvious that in RTMS \#147, the rainy observations are highly affected by intense rainfall. In order to prevent the misevaluation of the results, the intensity of rain during the congestion and average discharge flow reductions are evaluated together. Obvious effect of rain is clearly seen in Figure 5a for RTMS \#147. Both lower speed and capacity are observed at free flow conditions, while there is almost no change for congested flow.

Section II: Similar FFSs are observed for both RTMS \#414 and \#89 in sunny and rainy days. Besides, the averages of rainy and sunny discharge flows of both RTMSs are almost equal at each condition, separately. Consequently, the reduction of discharge flows is identical at $16 \%$ for both RTMSs. The average rain precipitation for RTMS \#89 is $1.62 \mathrm{~mm} / \mathrm{m}^{2} / \mathrm{h}$, while for RTMS \#414 it is $1.65 \mathrm{~mm} / \mathrm{m}^{2} / \mathrm{h}$, which are almost identical. Nearly an equal amount of rain precipitation causes the same amount of reduction in discharge flows in this section. The typical speed-flow rate relationship difference is given between rainy and sunny days for RTMS \#89 at this section in Figure $5 b$.
Section III: The lowest FFSs were observed in RTMS \#4 and \#323, among others, respectively $88 \mathrm{~km} / \mathrm{h}$ and $84 \mathrm{~km} / \mathrm{h}$ for sunny days. Additionally, in rainy conditions, a $6-8 \mathrm{~km} / \mathrm{h}$ reduction was observed in FFSs. In Figure 5c, the change in flow-speed relationship is shown for RTMS \#323 in this section. Due to the lowest FSSs, the lowest reduction in discharge flows is observed as well. Consequently, for both RTMSs, a 5\% reduction occurs in discharge flows observed between rain and sunny days. In this section, average rain intensity observed amounted to $1.36 \mathrm{~mm} / \mathrm{m}^{2} / \mathrm{h}$ for RTMS \#4 and $1.16 \mathrm{~mm} / \mathrm{m}^{2} / \mathrm{h}$ for RTMS \#323.

Section IV: The sunny FFSs of those two RTMSs in this section show a difference of $5 \mathrm{~km} / \mathrm{h}$, and the average reduction under rain is $4-7 \mathrm{~km} / \mathrm{h}$. The effect of rain in this section clearly appears in the flow-speed relationship, which is given in Figure $5 d$ for RTMS \#323. As an average, the rain precipitation of $2.29 \mathrm{~mm} / \mathrm{m}^{2} / \mathrm{h}$ affects rainy discharge flows for RTMS \#61, and 1.61 $\mathrm{mm} / \mathrm{m}^{2} / \mathrm{h}$ for RTMS \#329. The average reduction in discharge flow is found to be $24 \%$ for RTMS \#61, and $14 \%$ for RTMS \#329, which is consistent with rain precipitation, as higher precipitation causes bigger reduction.

In order to clarify the number of discharge flow occurrences obtained from those four sections, percent frequency distribution is used, and the discharge flows are grouped within each $200 \mathrm{pcu} / \mathrm{h} /$ lane range from $800 \mathrm{pcu} / \mathrm{h} /$ lane to 2,200 pcu/h/lane given in Figure 6.

The maximum frequency for sunny days is $61 \%$ in the 1,600-1,800 pcu/h/lane group, while the lowest are 5\% and $1 \%$ in the 1,200-1,400 and 2,000-2,200 groups, respectively. Unlike sunny days, rainy days' distribution appears as more scattered, with maximum frequencies at $31 \%$ in the $1,400-1,600$ group and $27 \%$ in the 1,600-1,800 group. Initial analyses indicate that rain has a reductive effect on discharging

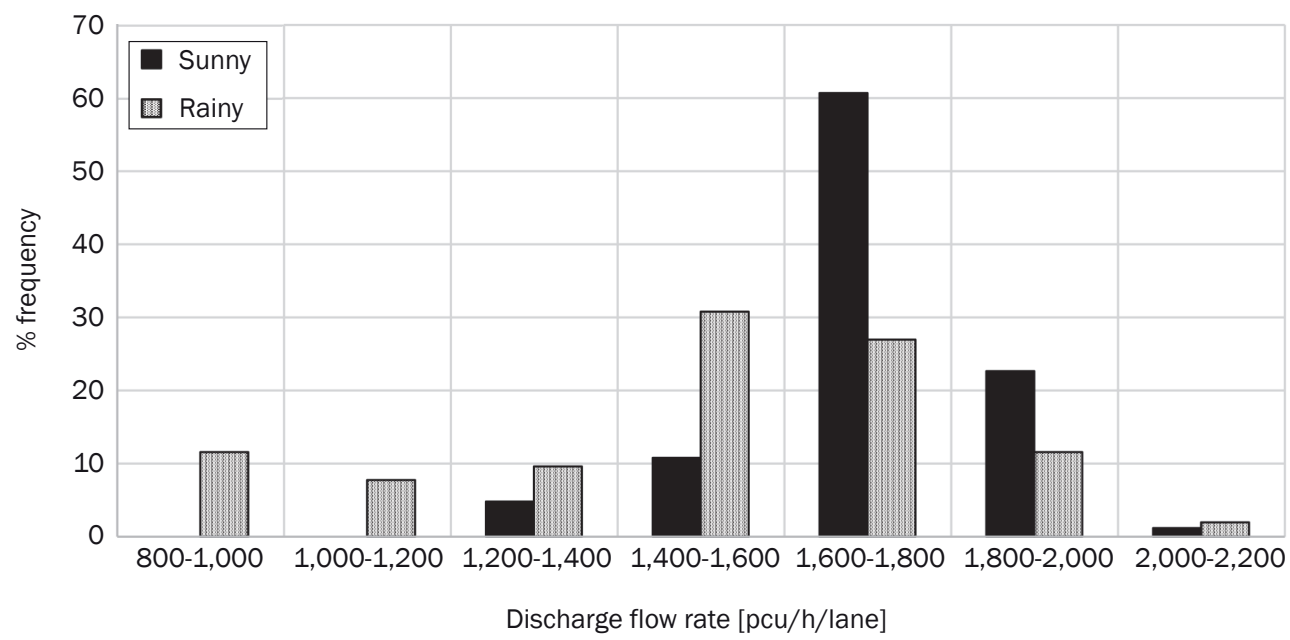

Figure 6 - Frequency distribution of discharge flows 
flows. To make a more comprehensive analysis, a total of 52 different discharge flows under rainy conditions are analyzed with their rain precipitations $\left(\mathrm{mm} / \mathrm{m}^{2} / \mathrm{h}\right)$.

The existence of an inverse relationship between discharge flow and rain precipitation is revealed from the observations. In order to consider the difference between sites, FFSs of each section for sunny days, which are given in Table 1, are similarly used. In the dataset, the rain precipitations have a range of 0.23 $\mathrm{mm} / \mathrm{m}^{2} / \mathrm{h}$ to $4.57 \mathrm{~mm} / \mathrm{m}^{2} / \mathrm{h}$; the discharge flows change from $886 \mathrm{pcu} / \mathrm{h} /$ lane to $2,017 \mathrm{pcu} / \mathrm{h} /$ lane, and FFSs take values between $84 \mathrm{~km} / \mathrm{h}$ and 104 $\mathrm{km} / \mathrm{h}$.

Congestion starting time and its duration may show a variation in each occurrence. Similarly, rain can start before or after congestion. However, as the aim of this paper is to analyze discharge flow change under the effect of rain, neither congestion duration nor capacity drop amount are taken into consideration. From this point of view, even if rain starts after bottleneck activation, discharge flow is taken into consideration.

From this perspective, two possibilities exist for the effect of rainfall on congested vehicles:

1) Rainfall starts after onset of congestion

2) Rainfall starts before onset of congestion (in free flow conditions)

For the first situation, the total rain precipitation is calculated until the observation of discharge flow. In the second situation, the rain precipitation is calculated from the beginning of congestion (Point $A$ in Figure 4) until the discharge flow.

With respect to these explanations, a multiple regression model is considered, where the discharge flow is dependent, and the rain precipitation and FFSs of sunny days are independent variables. The multiple regression model is presented in Equation 1.

$Q_{\text {dis }}=2,564.67-176.33 \cdot R-7.97 \cdot F F S_{S}$

where $R$ represents the rain precipitation $\left(\mathrm{mm} / \mathrm{m}^{2} / \mathrm{h}\right)$ during congestion, $F F S_{S}$ refers to free flow speed $(\mathrm{km} / \mathrm{h})$ of that road section in sunny days, and $Q_{\text {dis }}$ is the discharge flow in $\mathrm{pcu} / \mathrm{h} /$ lane. Even though the non-linear relationships between variables are investigated, the best fitted multiple regression model is determined in linear form. Consequently, the multiple regression model is estimated as linear form, and the coefficient of determination is found to be 0.63 for Equation 1. The result of this model is shown in Figure 7 with different FFSs $84 \mathrm{~km} / \mathrm{h}$ (observed lowest), $94 \mathrm{~km} / \mathrm{h}$ (average of all), and $104 \mathrm{~km} / \mathrm{h}$ (observed highest).

This model reveals that if the FFS of a road section is high, discharge flows tend to be low. Thus, it can be concluded that roads with high FFSs have more unstable flow states. For the lowest FFSs, the model indicates the results vice versa. From Equation 1, for the same rain precipitation, the difference of discharge flows between FFSs of $84 \mathrm{~km} / \mathrm{h}$ and $104 \mathrm{~km} / \mathrm{h}$ is calculated as $159 \mathrm{pcu} / \mathrm{h} /$ lane. As discharge flow shows high variation in sunny days, as mentioned in the literature, its variation in rainy days is similarly reasonable. Additionally, a change in discharge flow with FFS makes it more comprehensible.

Figure 7 shows discharge flows with respect to rain precipitation and FFSs. In other words, Equation 1 can only be used to calculate the discharge flows in rainy conditions. Moreover, this equation estimation is limited by the boundaries of independent variables. The rain precipitation varies between $0.23 \mathrm{~mm} / \mathrm{m}^{2} / \mathrm{h}$ and $4.57 \mathrm{~mm} / \mathrm{m}^{2} / \mathrm{h}$, while FFSs vary between $94 \mathrm{~km} / \mathrm{h}$ to $104 \mathrm{~km} / \mathrm{h}$.

Additionally, discharge flow changes are compared with sunny cases. For a more comprehensible percentage reduction model, the calculations lead to Figure 8. This figure proves that the increase of the rain precipitation causes an increase of percent reduction in discharge flows compared to sunny cases. The percent reductions are found to be compatible with Figure 7 , however, Figure 8 is comparatively more scattered.

In order to clarify the percent reduction of discharge flow, a quadratic regression model is estimated by using same independent variables as given in Equation 1. Linear and non-linear relationships are in-

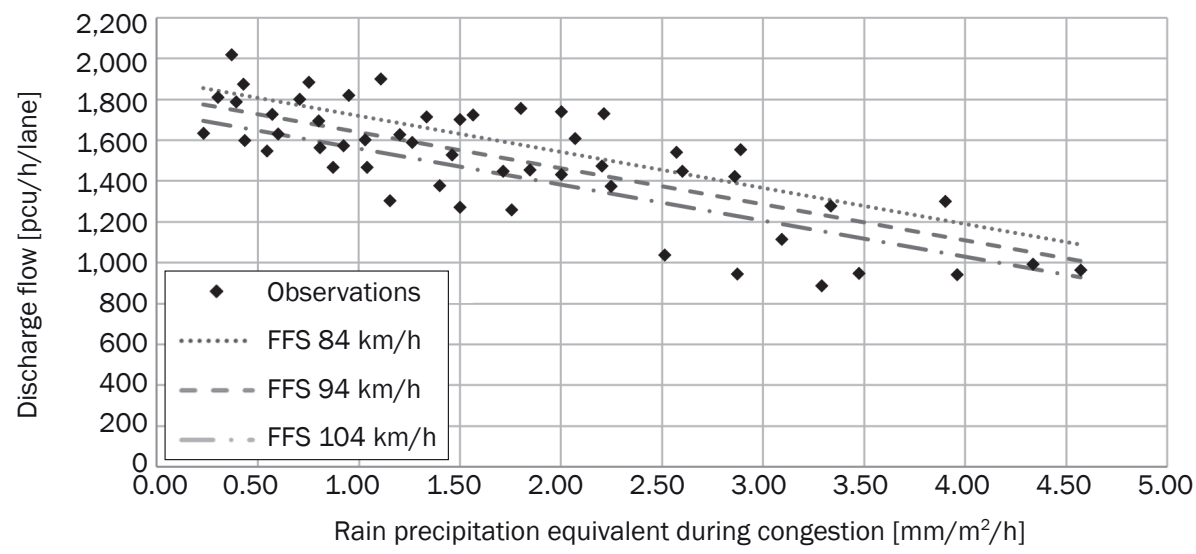

Figure 7 - Reduction in discharge flow with increasing rain precipitation and FFSs 


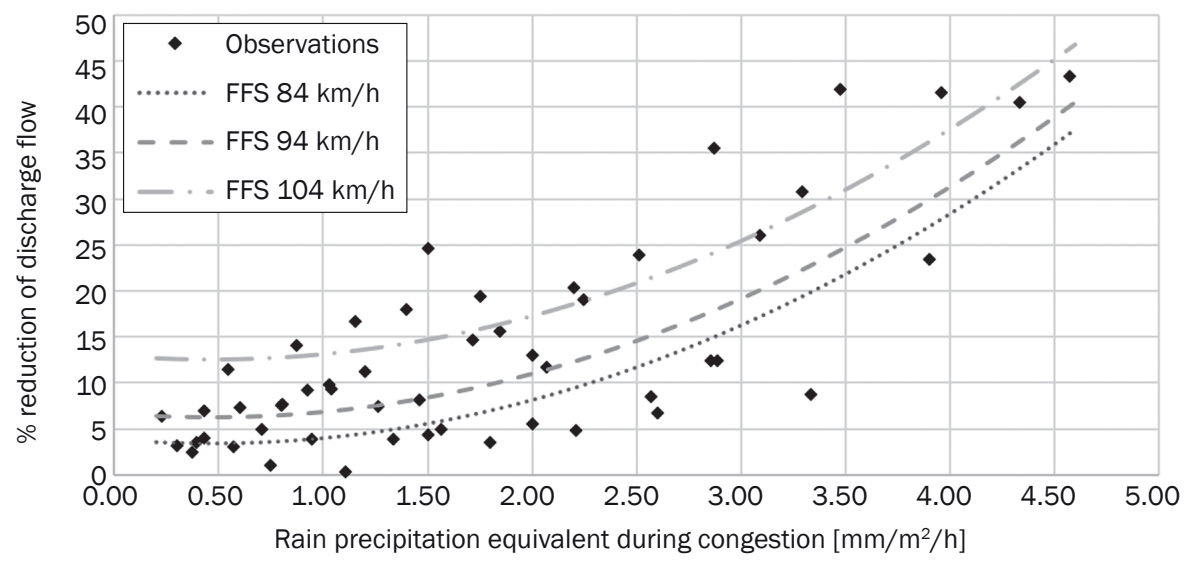

Figure 8 - Percent reduction in discharge flow compared to sunny conditions with increasing rain intensity

vestigated between variables, and non-linear form is found with a higher coefficient of determinations for both variables in the percent reduction model. The estimated quadratic regression model for percent reductions can be expressed in Equation 2, at the same time shown in Figure 8.

$$
\begin{aligned}
R Q_{\text {dis }}= & 112.18-1.84 \cdot R+1.99 \cdot R^{2}- \\
& -2.70 \cdot F F S_{S}+0.02 \cdot F F S_{S}^{2}
\end{aligned}
$$

where $R$ represents the rain precipitation in $\mathrm{mm} / \mathrm{m}^{2} / \mathrm{h}$ during congestion, $F F S_{S}$ is the free flow speed on sunny days, and $R Q_{\text {dis }}$ is the percentage reduction of discharge flow. The coefficient of determination is calculated as 0.70 for this model, and it should not be forgotten that this model is only valid when the precipitation changes from $0.23 \mathrm{~mm} / \mathrm{m}^{2} / \mathrm{h}$ to $4.57 \mathrm{~mm} / \mathrm{m}^{2} / \mathrm{h}$. Additionally, FFS change lies between $84 \mathrm{~km} / \mathrm{h}$ and $104 \mathrm{~km} / \mathrm{h}$.

Figure 8 includes the change of discharge flow percent reduction in relation to the change of FFS of that road section on sunny days. Discharge flow percent reduction was comparatively found to be lower for low FFSs. For instance, for the $2 \mathrm{~mm} / \mathrm{m}^{2} / \mathrm{h}$ rain precipitation, discharge flow reduction is found to be $8.1 \%$ at FFS of $84 \mathrm{~km} / \mathrm{h}$, while $17.3 \%$ at FFS of $104 \mathrm{~km} / \mathrm{h}$, according to Equation 2.

\section{CONCLUSION}

This paper analyzes the change of discharge flow under the effect of rain with a comparison to sunny days from the macroscopic perspective. Istanbul's urban motorways were selected as the study area and the reduction of discharge flow is observable in rainy periods when compared to sunny periods. It should not be forgotten that the reduction, which was calculated in this study, is not the capacity or capacity drop under rainy conditions, but rather the change of discharge flow with rain precipitation and compared to sunny conditions.
It was observed that the discharge flow rate of a same section is not constant; it tends to change with high standard deviations, even in sunny days. Similarly, the observed discharge flows under rain were found to be as scattered as in sunny conditions, and their standard deviations might be even higher compared to sunny days. Additionally, rainy discharge flow frequencies are more scattered than in sunny conditions. They are too far away to cluster within one or two groups and have a high standard deviation.

It was revealed that the average discharge flow reduction is very closely related to rain precipitation during congestion. The highest average rain precipitation was observed on RTMS \#147, amounting to 3.55 $\mathrm{mm} / \mathrm{m}^{2} / \mathrm{h}$ and causing a $37 \%$ reduction in discharge flow compared to sunny days. This relationship is explained in Equation 1, meaning that every $1.00 \mathrm{~mm} /$ $\mathrm{m}^{2} / \mathrm{h}$ of rain precipitation reduces the discharge flow by approximately $176 \mathrm{pcu} / \mathrm{h} /$ lane.

Moreover, a road section's FFS has an influence on discharge flows. If FFS is high, lower discharge flows are observed. According to Equation 1, for each $1 \mathrm{~km} / \mathrm{h}$ of speed increase, FFS reduces the discharge flow by $7.97 \mathrm{pcu} / \mathrm{h} /$ lane. Additionally, the discharge flow difference between FFSs of $84 \mathrm{~km} / \mathrm{h}$ and $104 \mathrm{~km} / \mathrm{h}$ was found to be $159 \mathrm{pcu} / \mathrm{h} /$ lane, according to Equation 1. In other words, when the same amount of precipitation occurs during congestion, discharge flow tends to be $159 \mathrm{pcu} / \mathrm{h} /$ lane higher at FFS of $84 \mathrm{~km} / \mathrm{h}$ compared to when FFS amounts to $104 \mathrm{~km} / \mathrm{h}$.

The comparison between discharge flows observed during sunny and rainy days similarly revealed a change in discharge flows. According to Equation 2, when $2 \mathrm{~mm} / \mathrm{m}^{2} / \mathrm{h}$ precipitation occurred, the percent reduction in the discharge flow amounted to $8.1 \%$ for FFS 84 km/h, and 17.3\% for FFS 104 km/h.

The practical application of rain precipitation $(R)$ shows how rain decreases discharge flow. Model development could not be sufficient to provide enough information to drivers, especially in real time, since discharge flow is meaningless on its own. This paper 
helps to develop weather responsive traffic management strategies for the operators. The discharge flow determination helps to change the speed limits simultaneously, with variable message sign application and to prevent the activation of bottlenecks on motorways. Since queue discharge flow is directly related to road section capacity, its amount obviously affects congestion levels. The amount of reduction during rain may cause longer congestion periods, with increased delays. Obviously, if the discharge flow amount is well known, more reliable traffic management strategies can be applied.

This study is concerned with a different perspective on analyzing discharge flows. It points out that not only the rain impact itself but also rain precipitation during congestion should be considered. For further studies, road geometry (gradient, lane width, etc.), traffic flow structure, visibility, day/night, and pavement surface conditions can be taken into account to investigate the effect of rain on discharge flows. In this study, as identical road geometries were present at each section, the effect of road geometry could not be analyzed.

Future studies should also focus on capacity drop determination under rainy and sunny conditions. Identification of its effects could be useful for the development of traffic management strategies. Possible effects of snow, fog and visibility, day/night difference, and dry/wet road surface should be analyzed similarly to obtain more comprehensible models.

GÖKER AKSOY, Ph.D. Candidate. ${ }^{1}$

e-mail: gokeraksoy@itu.edu.tr

KEMAL SELÇUK ÖĞÜT, Ph.D. ${ }^{1}$

e-mail: oguts@itu.edu.tr

1 İstanbul Teknik Üniversitesi

İnşaat Mühendisliği Bölümü

Istanbul, 34469, Türkiye

\section{KENT IÇi OTOYOLLARDA KUYRUK DAĞILMA AKIMININ YAĞMUR ETKISI ALTINDA DEĞişiMi}

\section{ÖZET}

Kent içi otoyollarda, talebin kapasiteyi aşması durumunda, kuyruk dağılma akımları sıkça görülmektedir. Kuyruk oluştuğunda, tıkanıklığın etkileri ortaya çıkar ve akım aşağı yönden geçebilen taşıt sayısı azalır. Bu durum, kapasite düşüşü olarak tanımlanır ve yol kapasitesi ile kuyruk dağılma akımının farkı alınarak hesaplanır. Tıkanıklığın oluşmasından sonra yaşanan bu kapasite düşüşü, kar ya da sis etkisi altında daha uzun kuyruk oluşumuna ve gecikmelere neden olmaktadır. Bu çalışmada, İstanbul kent içi otoyollarında, yağmurun kuyruk dağılma akımına etkisi incelenerek güneşli günlerle karşılaştırmalar yapılmıştır. Ayrıca, tıkanıklık süresince etkiyen yağış niceliğinin kuyruk dağılma akımına etkisi incelenmiştir. Dört farklı otoyol kesiminde yapılan çözümlemelerde, güneşli ve yağmurlu günler arasında, kuyruk dağılma akımında \%37'ye varan azalmalar belirlenmiştir. Yüksek serbest akım hızına (SAH) sahip otoyol kesimlerinin, düşük SAH'lı otoyol kesimlerine göre yağmur- dan daha çok etkilendiği bulunmuştur. Tıkanıklık boyunca, $1 \mathrm{~mm} / \mathrm{m} 2 / \mathrm{sa}$ yağ/şın etkimesi durumunda, SAH'ı 84 km/sa olan otoyol kesimlerinde kuyruk dağılma akımı 1719 bo/sa/ şrt olarak bulunurken, SAH'ı 104 km/sa olan otoyol kesimlerinde bu akım 1560 bo/sa/șrt olarak belirlenmiștir.

\section{ANAHTAR KELIMELER}

kuyruk dağılma akımı; kapasite düşüşü; yağmur etkisi; otoyol;

\section{REFERENCES}

[1] Banks JH. Two-Capacity Phenomenon at Freeway Bottlenecks: A Basis for Ramp Metering? Transportation Research Record: Journal of the Transportation Research Board. 1991;1320: 83-90.

[2] Banks JH. The Two-Capacity Phenomenon: Some Theoretical Issues. Transportation Research Record: Journal of the Transportation Research Board. 1991;1320: 234-241.

[3] Hall FL, Agyemang-Duah K. Freeway Capacity Drop and the Definition of Capacity. Transportation Research Record: Journal of the Transportation Research Board. 1991;1320: 91-98.

[4] Rijavec R, Semrov D. Effects of Weather Conditions on Motorway Lane Flow Distributions. Promet - Traffic \& Transportation. 2017;30(1): 83-92.

[5] Papageorgiou M, Hadj-Salem H, Blosseville JM. ALINEA: A Local Feedback Control Law for On-ramp Metering. Transportation Research Record: Journal of the Transportation Research Board. 1991;1320: 58-64.

[6] Papageorgiou M, Diakaki C, Dinopoulou V, Kotsialos A, Wang Y. Review of Road Traffic Control Strategies. Proceedings of the IEEE. 2003:91(12): 2043-2067.

[7] Cassidy MJ, Rudjanakanoknad J. Increasing the Capacity of an Isolated Merge by Metering its On-ramp. Transportation Research Part B: Methodological. 2005:39(10): 896-913.

[8] Elefteriadou L, Lertworawanich P. Defining, Measuring and Estimating Freeway Capacity. Transportation Research Board $82^{\text {nd }}$ Annual Meeting compendium of papers CD-ROM, January 12-16, 2003, Washington, DC; 2003.

[9] Chung K, Rudjanakanoknad J, Cassidy MJ. Relation Between Traffic Density and Capacity Drop at Three Freeway Bottlenecks. Transportation Research Part B: Methodological. 2007;41(1): 82-95.

[10] Yuan K, Knoop VL, Leclercq L, Hoogendoorn SP. Capacity Drop: A Comparison Between Stop-and-Go Wave and Queue Congestion at Lane-Drop Bottleneck. Transportmetrica B: Transport Dynamics. 2017;5(2): 145-158.

[11] Öğ̈̈t KS, Banks JH. Stability of Freeway Bottleneck Flow Phenomena. Transportation Research Record: Journal of the Transportation Research Board. 2005;1934: 108-115.

[12] Lakshmi K, Öğ̈̈t KS, Banks JH. Evaluation of N-Curve Methodology for Analysis of Complex Bottlenecks. Transportation Research Record: Journal of the Transportation Research Board. 1999;2007: 54-61.

[13] Bertini RL, Malik S. Observed Dynamic Traffic Features on Freeway Section with Merges and Diverges. Transportation Research Record: Journal of the Transportation Research Board. 2004;1867: 25-35. 
[14] Bertini RL, Leal M. Empirical Study of Traffic Features at a Freeway Lane Drop. ASCE Journal of Transportation Engineering. 2005;131(6): 397-407.

[15] Cassidy MJ, Bertini RL. Some Traffic Features at Freeway Bottlenecks. Transportation Research Part B: Methodological. 1999;33: 25-42.

[16] Oh S, Yeo H. Estimation of Capacity Drop in Highway Merging Sections. Transportation Research Record: Journal of the Transportation Research Board. 2012;2286: 111-121.

[17] Jones ER, Goolsby ME. Effect of rain on freeway capacity. Texas Transportation Institute, Texas A\&M University College Station. Research Report Number 24-23, 1969.

[18] Kleitsch KL, Cleveland DE. The effect of rainfall on freeway capacity. Highway Safety Research Institute, The University of Michigan. Final Report, HSRI Report No. TrS-6, 1971.

[19] Brilon W, Ponzlet M. Variability of speed-flow relationships on German autobahns. Transportation Research Record: Journal of the Transportation Research Board. 1996;1555: 91-98.
[20] Balke K, Songchitruksa P, Liu H, Brydia R, Jasek D, Benz R. Concepts for managing freeway operations during weather events. Texas Transportation Institute, The Texas A\&M University System College Station. Technical Report No. FHWA/TX-07/0-5278-1, 2007.

[21] Hranac R, Sterzin E, Krechmer D, Rakha H, Farzaneh M. Empirical studies on traffic flow in inclement weather. Cambridge Systematics and Virginia Tech Transportation Institute. Technical Report No. FHWAHOP-07-073, 2006.

[22] Holdener DJ. The effect of rainfall on freeway speeds. Institute of Transportation Engineers Journal. 1998; 68 (11): $16 \mathrm{p}$.

[23] Jia A, Williams B, Rouphail N. Identification and Calibration of Site-Specific Stochastic Freeway Breakdown and Queue Discharge. Transportation Research Record: Journal of the Transportation Research Board. 2010;2188: 148-155.

[24] Transportation Research Board. Highway Capacity Manual. Washington DC: Transportation Research Board, National Research Council; 2010. 